\title{
Sharing, Liking, Commenting, and Distressed? The Pathway Between Facebook Interaction and Psychological Distress
}

\author{
Wenhong Chen, PhD, and Kye-Hyoung Lee, $\mathrm{MA}^{2}$
}

\begin{abstract}
Studies on the mental health implications of social media have generated mixed results. Drawing on a survey of college students $(N=513)$, this research uses structural equation modeling to assess the relationship between Facebook interaction and psychological distress and two underlying mechanisms: communication overload and self-esteem. It is the first study, to our knowledge, that examines how communication overload mediates the mental health implications of social media. Frequent Facebook interaction is associated with greater distress directly and indirectly via a two-step pathway that increases communication overload and reduces self-esteem. The research sheds light on new directions for understanding psychological well-being in an increasingly mediated social world as users share, like, and comment more and more.
\end{abstract}

\section{Introduction}

$\mathbf{S}^{\mathrm{a}}$ OCIAL NETWORKING SITES (SNSs) have become an integral part of everyday life. Most studies on SNSs have centered on identity, network building, or privacy issues. ${ }^{1,2}$ In comparison, research on SNS implications for psychological wellbeing is in the early stage and results remain inconclusive. This research assesses the relationship between Facebook interaction and psychological distress and how they are linked via communication overload and self-esteem.

\section{Internet use, SNS use, and psychological well-being}

The Internet implications for psychological well-being have generated considerable attention but mixed results.,4 Some studies revealed that Internet use was associated with depression, loneliness, and stress, especially among heavy users or users who lacked social skills. ${ }^{5-7}$ For example, frequent instant messaging was associated with lower life satisfaction and greater depression. ${ }^{3,8}$ Other studies, however, provided support for a positive relationship between Internet use and psychological well-being. ${ }^{9}$ For instance, greater involvement with online communities was related to lower levels of stress. ${ }^{10,11}$ In addition, a few studies suggested that Internet use was not related to psychological well-being. ${ }^{12,13}$ Factors contributing to these conflicting results may include how key concepts such as Internet use and psychological well-being were measured, at which stage of Internet diffu- sion the study was conducted, or sociodemographic characteristics of the research population. ${ }^{6,14}$

The emerging literature on SNSs and psychological wellbeing has been inconsistent too. Some studies showed that greater SNS engagement was associated with psychological well-being such as feeling good about oneself or feeling closer to other people. ${ }^{15,16}$ One early study showed that neither the number of SNS friends nor the time spent on SNSs was related to loneliness. ${ }^{13}$ Yet, more recent studies were less optimistic and found that SNSs created negative experience on $\mathrm{SNSs}^{17}$ and face-to-face confrontations or troubles at work. ${ }^{18}$

The literature has considered several social and psychological mechanisms that may link the relationship between Internet/Facebook use and psychological distress. First, in the late 1990s, the time-displacement hypothesis assumed a trade-off between time spending online and face-to-face with family and friends. ${ }^{19,20}$ However, a growing body of literature since then has shown that the relationship between Internet use and sociability is positive or neutral. ${ }^{21}$ Second, digital communication has been a lean mode of communication and the reduced nonverbal cues may increase stress. ${ }^{7,22}$ It has been also argued that the lean mode of communication was more attractive to users who had low self-presentation skills and thus preferred online over face-to-face communication, which in turn led to negative outcomes of Internet use such as missing class or work or getting in trouble at work or school. ${ }^{23}$ More recently, one mechanism-Facebook envyhas entered popular parlance. SNS users often share their

\footnotetext{
${ }^{1}$ Department of Radio-Television-Film, College of Communication, and ${ }^{2}$ Department of Educational Administration, College of Education, University of Texas at Austin, Austin, Texas.
} 
most positive experience in the effort of constructing an appealing online persona. Studies, however, show that such self-presentation is good for their happiness ${ }^{16}$ but bad for their self-esteem. ${ }^{24,25}$ Moreover, as more frequent Facebook users tend to have greater exposure to other users' positive self-presentation, they often feel that others have better lives than themselves. ${ }^{26}$ The feelings of relative deprivation can increase psychological distress. ${ }^{27}$

In this research, we focus on the frequency of Facebook interaction defined as how frequently users interact with other individuals or groups through symbolic exchanges of information and emotion via sharing, liking, and commenting on Facebook. Given the rapid changes of SNS usage patterns since the early 2000s, we align with more recent studies and hypothesize that

H1: The frequency of Facebook interaction is positively related to psychological distress.

\section{Searching for the mechanisms}

On top of the main effect, we focus on two mechanisms that may link Facebook interaction and distress: communication overload and self-esteem. Communication overload happens when people feel overloaded by a vast amount of complex communication input from diverse sources, multiple channels, with rapid turnaround time, ${ }^{28,29}$ which can lead to stress and depression. ${ }^{30-33}$ Information overload occurs when people receive more information than they can process, which may result in poor decision making, loss of motivation, stress, depression, and physical and emotional fatigue. ${ }^{34,35}$ The two concepts overlap and we choose to use the term "communication overload" since it captures the feelings of being overloaded via communicative interaction involving symbolic exchanges of information and emotion. ${ }^{36,37}$

Internet and social media use can increase communication overload. Boyd discussed four properties that restructured communication in the social media environment: persistence, replicability, scalability, and searchability. ${ }^{38}$ Information is easy to search, replicate, and spread but difficult to delete completely. The potential audience who can access what is shared can be dramatically larger and more diverse than the target audience a user may have in mind. As information traverses from one social setting to another, the collapsed boundaries between different social contexts may create misunderstanding and tarnish reputation. ${ }^{18}$

Facebook interaction clearly has these properties. By the end of 2011, Facebook users uploaded 250 million photos and they clicked the like button 2.7 billion times every day. ${ }^{39}$ As a tool of self-promotion ${ }^{24}$ and social surveillance, ${ }^{40}$ Facebook interaction may increase the volume, sources, and complexity of communication and thus lead to communication overload. As the negative relationship between communication overload and psychological well-being is well established in the literature, we argue that communication overload may provide a pathway linking Facebook interaction and psychological distress.

$\mathrm{H} 2 \mathrm{a}$ : Facebook interaction is positively related to communication overload.

$\mathrm{H} 2 \mathrm{~b}$ : Communication overload mediates the relationship between Facebook interaction and psychological distress.

A second mechanism we examine in this research is selfesteem, "the most fundamental manifestation of core self- evaluations, ${ }^{\prime 41(p . ~ 80)}$ which has a well-established positive relationship with psychological well-being. ${ }^{42}$ Self-esteem can also moderate or mediate the health impacts of stressors. ${ }^{43}$ Yet, the literature on the relationship between Internet use and self-esteem has been mixed. ${ }^{44,45}$ Although some research suggested that Internet use ${ }^{9}$ and online chat ${ }^{11}$ increased selfesteem, a meta-analysis of 40 studies identified a detrimental effect of Internet use on self-esteem. ${ }^{6}$

The literature also remains inconclusive on the relationship between SNSs use and self-esteem. More frequent SNSs use or having more Facebook friends increased self-esteem. ${ }^{46}$ SNSs use increased psychological well-being, especially for college students with low self-esteem. ${ }^{15}$ Self-esteem also positively mediated the beneficial relationship between SNSs use and life satisfaction. ${ }^{3}$ However, more recent studies revealed that greater online activity, more time spent on Facebook, and more self-promotional Facebook use were negatively related to self-esteem. ${ }^{24,25,47}$ Because of the changes in SNS affordances, usage patterns, and user characteristics over time, we align with the meta-analysis ${ }^{6}$ and more recent studies. Furthermore, given the well-established positive relationship between self-esteem and psychological well-being, we argue that frequent Facebook interaction is indirectly related to distress via lower levels of self-esteem.

H3a: The frequency of Facebook interaction is negatively related to self-esteem.

H3b: Self-esteem mediates the relationship between Facebook interaction and psychological distress.

\section{Methods}

Data

This research draws on an online survey of college students in two introductory courses at a big public university in southwestern United States. Extra credit was offered by the course instructors to encourage participation. The authors were not the course instructors. A total of 594 students out of the 630 students enrolled in the two courses answered the survey from November 6 to December 10, 2011, yielding a response rate of $94 \%$ (AAPOR RR2). As 35 students failed to answer more than $50 \%$ of the questions, it lowered the response rate to $89 \%$ (AAPOR RR1). Only respondents with valid answers on all variables involved in the analyses here were included $(N=513)$.

\section{Measures}

The dependent variable psychological distress was measured by six items adapted from the Kessler Psychological Distress Scale. ${ }^{48}$ The respondents were asked in the past 30 days how often they felt (a) sad, (b) nervous, (c) restless or fidgety, (d) hopeless, (e) worthless, or (f) everything was an effort. Each item was measured by a five-point Likert-type scale $(1=$ none of the time and $5=$ all of the time). After conducting confirmatory factor analysis (CFA), item (e), worthless, was excluded because of cross loading over multiple constructs, which produced a poor model fit. The index thus included five items and was reliable (Cronbach's $\alpha=0.83$, mean $=11.47, S D=3.75$ ).

Facebook interaction was measured by eight items indicating the frequency of Facebook activities in the past 30 days via a seven-point Likert-type scale $(1=$ never and $7=\mathrm{a}$ few times an hour). 
Table 1. Summary of Unstandardized Descriptive Statistics and Bivariate Correlations

(2)

(3)

(4)

(5)

(6)

(7)

(1) Facebook interaction

(2) Communication overload

(3) Self-esteem

(4) Psychological distress

(5) Class

(6) Sex

(7) Race

Means

SD

Cronbach's alpha

$\begin{array}{cc}-\overline{195^{* * *}} & -\overline{147^{* * *}} \\ -0.104^{*} & -0.255^{* * *} \\ 0.177^{* * *} & 0.055 \\ -0.089^{*} & 0.026 \\ 0.057 & -0.035 \\ -0.113^{*} & 8.83 \\ 17.80 & 2.82 \\ 5.44 & 0.84 \\ 0.81 & \end{array}$

$-0 . \overline{499^{* * *}}$
0.085
0.005
$0.113^{*}$
14.40
3.40
0.80

$-\overline{0}$
-0.057
$0.312^{* * * *}$
3.34
0.89

$\overline{0.005}$

0.52

0.50 $\overline{0.64}$

0.48

The standardized descriptive statistics and correlation matrix are available upon request.

${ }^{*} p<0.05,{ }^{* *} p<0.01,{ }^{* * *} p<0.001$.

After conducting CFA, three items were excluded because of cross loading over multiple constructs, which produced a poor model fit. Five items were included: (a) upload and share photos; (b) share web links, news stories, blog posts, and notes; (c) "like" or comment on people's status, wall, links, or photos; (d) "like" or comment on Facebook pages of groups, events, organizations, or companies; and (e) click the "like" or "share" button on a non-Facebook website to share it on Facebook. The index was reliable (Cronbach's $\alpha=0.81$; mean $=17.80, S D=5.44$ ).

Communication overload was measured by five items adapted from previous research. ${ }^{36,37}$ Each item was measured by a five-point Likert-type scale $(1=$ strongly disagree and $5=$ strongly agree). After conducting CFA, two items were excluded because of cross loading over multiple constructs, which produced a poor model fit. Three items were included: (a) I feel that I generally have too many phone calls, meetings, face-to-face conversations, e-mails, text messages, etc.; (b) I receive more information than I can process; and (c) I feel overloaded with information. The index was reliable (Cronbach's $\alpha=0.84$, mean $=8.83, S D=2.82$ ).

Self-esteem was measured by seven items adapted from the Rosenberg Self-Esteem Scale, ${ }^{42}$ using a five-point Likert-type scale $(1=$ strongly disagree and $5=$ strongly agree). After conducting CFA, three items were excluded because of cross loading over multiple constructs, which produced a poor model fit. Four items were included: (a) on the whole I am satisfied with myself, (b) at times I think that I am no good at all (reversed), (c) I feel I do not have much to be proud of (reversed), and (d) I wish I could have more respect for myself (reversed). The index was reliable (Cronbach's $\alpha=0.80$, mean $=14.40, S D=3.40$ ).

Sociodemographic characteristics, including class, race, and sex, were controlled as they were found to be associated with Facebook use ${ }^{49}$ or psychological distress. ${ }^{50}$ The respondents were asked to describe the class of their family growing up, measured by a five-point scale $(1=$ lower class and $5=$ upper class; mean $=3.34, S D=0.89)$. Race was measured by $1=$ white and $0=$ nonwhite, and $64 \%$ of the respondents were white. Sex was measured by $1=$ female and $0=$ male, and $52 \%$ of the respondents were women. Unstandardized means, $S D$, and correlations are reported in Table 1.

\section{Results}

We used structural equation modeling in Mplus 6.12 to test the hypothesized model (Fig. 1). Our analysis followed the two-step procedure: the measurement model and the structural model. ${ }^{51}$ The measurement model performed a CFA to examine whether individual items in a scale were good indicators of a latent construct. Four latent constructs, as discussed above, were included in the measurement model: the dependent construct psychological distress and three independent constructs Facebook interaction, communication overload, and self-esteem. The structural model was consisted of three sets of regressions: (a) psychological distress was regressed on Facebook interaction, communication overload, and selfesteem; (b) communication overload on Facebook interaction; and (c) self-esteem on Facebook interaction and communication overload. Class, sex, and race were controlled in the structural model.

\section{The measurement model}

Model (a) in Table 2 showed that the chi-square for the measurement model was significant $\left(\chi^{2}=229.70, d f=108\right.$, $p<0.001$ ), indicating an inadequate fit between the model and the observed data. Since the chi-square statistics were sensitive to the sample size, ${ }^{51,52}$ other model fit indices were considered. The Bentler comparative fit index (CFI) was 0.97, the TuckerLewis index (TLI) was 0.96, the root-mean-squared error of approximation (RMSEA) was 0.05 , and the standardized root mean of the residual (SRMR) was 0.05, indicating adequate model fit based on the thresholds of acceptable fit (CFI $\geq 0.95$, $\mathrm{TLI} \geq 0.90, \mathrm{RMSEA} \leq 0.05, \mathrm{SRMR} \leq 0.08)$. $^{53,54}$ Thus, the measurement model adequately measured the latent constructs in the data.

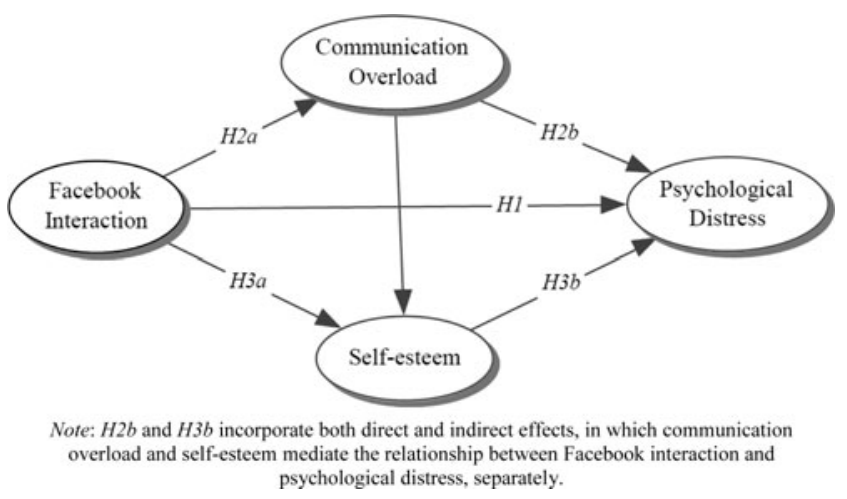

FIG. 1. Hypothesized model of the relationship between Facebook use and psychological distress. 
TABle 2. Summary of Fit Indicators

\begin{tabular}{lccccccccc}
\hline Models & $\chi^{2}$ & $\mathrm{df}$ & $\mathrm{p}$ & AIC & BIC & CFI & TLI & RMSEA & SRMR \\
\hline (a) Measurement model & 229.70 & 108 & 0.00 & 23629.59 & 23892.49 & 0.97 & 0.96 & 0.05 & 0.05 \\
(b) Hypothesized structural model & 294.45 & 145 & 0.00 & 27326.42 & 27678.36 & 0.95 & 0.94 & 0.05 & 0.04 \\
(c) Revised structural model & 296.14 & 146 & 0.00 & 27326.10 & 27673.81 & 0.95 & 0.94 & 0.05 & 0.04 \\
\hline
\end{tabular}

Note. The control variables were not included in the test of the measurement model.

AIC, Akaike Information Criterion; BIC, Bayesian Information Criterion; $d f$, Degree of freedom; CFI, comparative fit index; TLI, TuckerLewis index; RMSEA, root-mean-squared error of approximation; SRMR, standardized root mean of the residual.

\section{The hypothesized model}

Although the chi-square of the hypothesized model was significant $\left(\chi^{2}=294.45, d f=145, p<0.001\right)$ as shown in model (b) in Table 2, other fit statistics supported an adequate model fit $(\mathrm{CFI}=0.95, \mathrm{TLI}=0.94$, RMSEA $=0.05, \mathrm{SRMR}=0.04)$. We reported both unstandardized and standardized coefficients in Figures 2 and 3 but used the unstandardized coefficients in the text. ${ }^{51} \mathrm{H} 1$ was supported; that is, Facebook interaction was positively related with psychological distress $(b=0.120$, standard error (s.e.) $=0.048, t=2.47, p<0.05$ ).

$\mathrm{H} 2 \mathrm{a}$ on a positive relationship between Facebook interaction and communication overload was also supported $(b=0.144$, s.e. $=0.042, t=3.48, p<0.01)$. However, H2b that communication overload would mediate the relationship between Facebook interaction and psychological distress was rejected $(b=0.019$, s.e. $=0.010, t=1.811, p=0.07)$. H3a that Facebook interaction was negatively related with self-esteem was rejected $(b=-0.046$, s.e. $=0.036, t=-1.284, p=0.199)$. H3b that self-esteem would mediate the relationship between Facebook use and psychological distress was not supported either $(b=0.038$, s.e. $=0.030, t=1.280, p=0.201)$.

\section{The revised model}

The results in the hypothesized model suggested that Facebook interaction was not directly related to self-esteem. Thus, we excluded this relationship to achieve a more parsimonious model. Although the chi-square was significant as shown in model (c) in Table $2\left(\chi^{2}=296.14, d f=146, p<0.001\right)$, other fit statistics supported an adequate model fit for the revised model $(\mathrm{CFI}=0.95, \mathrm{TLI}=0.94, \mathrm{RMSEA}=0.05, \mathrm{SRMR}=0.04)$. Since the revised model was nested in the hypothesized model, the chi-square difference test showed that the

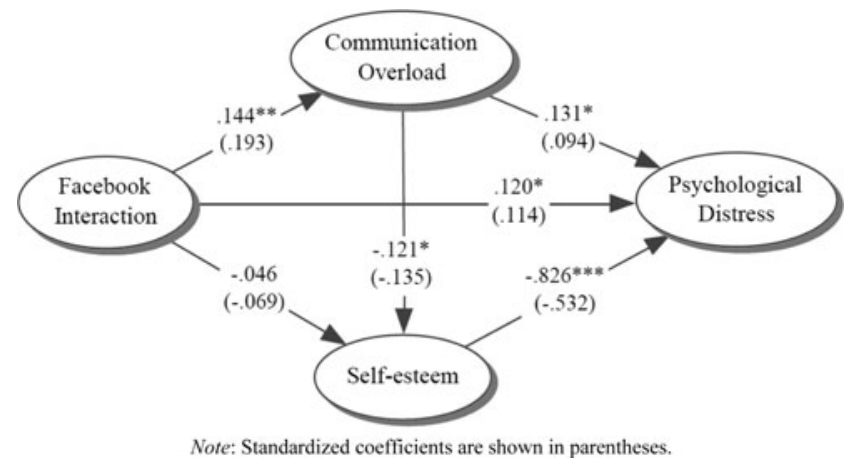

FIG. 2. Results for the test of the hypothesized model: model (b). hypothesized model did not significantly better explain the data than the revised model $\left(\Delta \chi^{2}=1.7, \Delta d f=1, p>0.05\right)$. Thus, the revised model (Fig. 3) was more parsimonious and preferred. ${ }^{55}$ Overall, $33.7 \%$ of the variance in psychological distress was explained in the revised model.

\section{Mediation}

Figure 3 shows that Facebook interaction was positively related to psychological distress. Communication overload was positively related to psychological distress. Self-esteem was negatively associated with psychological distress. Besides these direct effects, there were several significant indirect effects (Table 3). Self-esteem mediated the relationship between communication overload and psychological distress $(b=0.111$, s.e. $=0.039, t=2.882, p<0.01)$. More interestingly, Facebook interaction was indirectly and positively related to psychological distress via a two-step pathway as increased communication overload reduced self-esteem, which in turn led to greater psychological distress $(b=0.016$, s.e. $=0.007$, $t=2.270, p<0.05)$.

\section{Discussion and Conclusions}

The social implications of the Internet often depend on user characteristics and usage patterns. ${ }^{56}$ To reconcile mixed findings, ${ }^{57}$ we take into consideration a variety of Facebook interaction-relational, communicative, and informationaland find that more frequent Facebook interaction is associated with greater psychological distress. We explore two mechanisms underlying the relationship between Facebook interaction and distress: communication overload and selfesteem. The research makes a few contributions.

First, our finding lends support to more recent studies that the relationship between Facebook interaction and

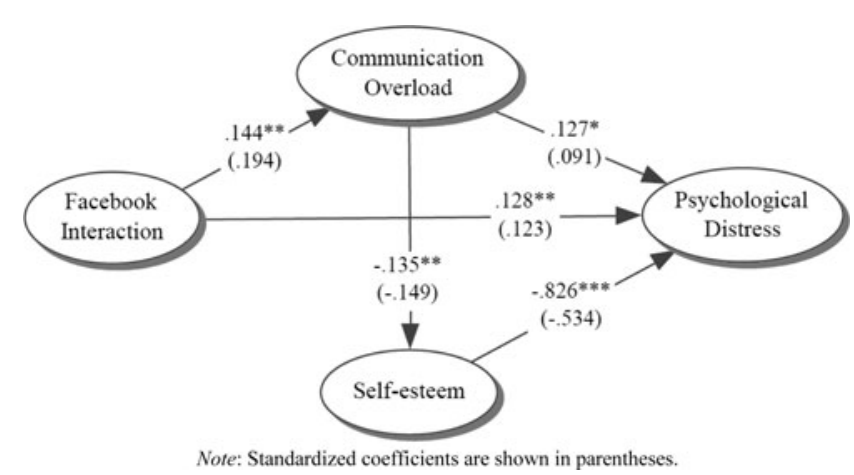

FIG. 3. Results for the test of the revised model: model (c). 
Table 3. Effect Decomposition from the Revised Model

\begin{tabular}{llrrr}
\hline Predictor & \multicolumn{1}{c}{ Criterion } & Direct effect & Indirect effect & Total effect \\
\hline Facebook & Communication overload & $0.194^{* *}(0.052)$ & - & $0.194^{* *}(0.052)$ \\
interaction & Self-esteem (via Communication overload) & - & $0.015^{*}(0.007)$ & $0.015^{*}(0.007)$ \\
& $\begin{array}{l}\text { Psychological distress (via Communication } \\
\quad \text { overload \& Self-esteem) }\end{array}$ & $0.123^{* *}(0.045)$ & $0.033^{*}(0.013)$ & $0.156^{* *}(0.046)$ \\
& Self-esteem & $-0.149^{* *}(0.049)$ & - & $-0.149^{* *}(0.049)$ \\
Communication & & $0.091^{*}(0.046)$ & $0.079^{* *}(0.027)$ & $0.170^{* *}(0.050)$ \\
overload & Psychological distress (via Self-esteem) & $-0.534^{* *}(0.043)$ & - & $-0.534^{* * *}(0.043)$ \\
Self-esteem & Psychological distress & & - & \\
\hline
\end{tabular}

Note. ${ }^{* * *} p<0.001 ;{ }^{* *} p<0.01 ;{ }^{*} p<0.05$ (standardized coefficients with standard errors in parenthesis).

psychological well-being tends to be negative. Second, this is the first study that applies the concept of communication overload to the mental health implications of social media. We identify a main effect and a mediating effect of communication overload on psychological well-being in nonorganizational setting, as previous studies have centered on the negative impacts of communication overload on urban infrastructure ${ }^{30,58}$ or job performance. ${ }^{37}$ More specifically, our findings reveal that although communication overload itself does not significantly mediate the relationship between Facebook interaction and distress, it does link them in a twostep pathway through reduced self-esteem. Third, the literature has been inconclusive about the relationship between Facebook use and self-esteem. ${ }^{6,59}$ Our analyses show that instead of a direct negative relationship between Facebook interaction and self-esteem, the two are linked indirectly through communication overload. On the one hand, our research supports more recent studies that the relationship between Facebook use and self-esteem is likely to be negative. ${ }^{24,25,47}$ On the other hand, we offer a more nuanced understanding by pointing to the mediation effect of communication overload.

This research has several limitations. First, the data are cross-sectional. We cannot rule out the possibility that psychological distress can lead to Facebook interaction. ${ }^{5}$ The relationship is likely to be reciprocal as the two may feed each other. Panel data are needed to offer a better understanding of the causal direction between Facebook interaction, communication overload, and distress. Second, although young people are more likely to engage with SNSs and thus provide a unique opportunity to understand the link between SNSs use and psychological well-being, the focus on college students limits the generalizability of the research. Future research needs to be expanded to the general population. Third, our measure of communication overload is general. Measure more specific to communication overload caused by Facebook use is needed in future research.

These caveats aside, this research has advanced a more comprehensive understanding of the complicated mental health implications of new communication and media technologies. Existing studies have examined time-displacement, envy, or psychological inclination as mechanisms that may link Facebook use and psychological well-being. This research, applying the concept of communication overload to the health implications of social media, sheds light on new directions for maintaining psychological well-being in an increasingly mediated social world in which users are expected to share, like, and comment more and more. We hope that it will inspire more research on the interrelations between Facebook interaction, communication overload, and self-esteem and their implications for psychological wellbeing.

\section{Acknowledgments}

The research draws data from the Social Media in Student Life Project funded by the Office of the Vice President for Research, University of Texas at Austin, and the Undergraduate Research Mentorship Award, College of Communication, University of Texas at Austin.

\section{Author Disclosure Statement}

No competing financial interests exist.

\section{References}

1. boyd dm, Ellison NB. Social network sites: definition, history, and scholarship. Journal of Computer-Mediated Communication 2007; 13(1). http://jcmc.indiana.edu/vol13/issue1/ boyd.ellison.html (accessed Jan. 1, 2013).

2. Livingston S, Baker D. On the rapid rise of social networking sites: new findings and policy implications. Children \& Society 2010; 24:75-83.

3. Valkenburg PM, Peter J, Schouten AP. Friend networking sites and their relationship to adolescents' well-being and social self-esteem. CyberPsychology \& Behavior 2006; 9:584590.

4. Cotten SR, Goldner M, Hale TM, Drentea P. The importance of type, amount, and timing of Internet use for understanding psychological distress. Social Science Quarterly 2011; 92:119-139.

5. Kim J, LaRose R, Peng W. Loneliness as the cause and the effect of problematic Internet use: the relationship between Internet use and psychological well-being. CyberPsychology \& Behavior 2009; 12:451-455.

6. Huang C. Internet use and psychological well-being: a metaanalysis. CyberPsychology, Behavior, and Social Networking 2010; 13:241-249.

7. Kraut R, Kiesler S, Boneva B, et al. Internet paradox revisited. Journal of Social Issues 2002; 58:49-74.

8. van den Eijnden RJ, Meerkerk G, Vermulst A, et al. Online communication, compulsive Internet use, and psychosocial well-being among adolescents: a longitudinal study. Developmental Psychology 2008; 44:655-665.

9. Mesch G, Talmud I. The quality of online and offline relationships: the role of multiplexity and duration of social relationships. The Information Society 2006; 22:137-148. 
10. Wright K. Perceptions of online support providers: an examination of perceived homophily, source credibility, communication and social support within on-line support groups. Communication Quarterly 2000; 48:44-59.

11. Shaw LH, Gant LM. In defense of the Internet: the relationship between Internet communication and depression, loneliness, self-esteem, and perceived social support. CyberPsychology \& Behavior 2002; 5:157-171.

12. Chen Y, Persson A. Internet use among young and older adults: relation to psychological well-being. Educational Gerontology 2002; 28:731-744.

13. Vergeer M, Pelzer B. Consequences of media and Internet use for offline and online network capital and well-being: a causal model approach. Journal of Computer-Mediated Communication 2009; 15:189-210.

14. Bessière K, Kiesler S, Kraut R, Boneva BS. Effects of internet use and social resources on changes in depression. Information Communication and Society 2008; 11:47-70.

15. Ellison NB, Steinfield C, Lampe C. The benefits of Facebook "friends": social capital and college students' use of online social network sites. Journal of Computer-Mediated Communication 2007; 12(4). http://jcmc.indiana.edu/vol12/ issue4/ellison.html (accessed Jan. 1, 2013).

16. Kim J, Lee JR. The Facebook paths to happiness: effects of the number of Facebook friends and self-presentation on subjective well-being. CyberPsychology, Behavior, and Social Networking 2011; 14:359-364.

17. Tokunaga RS. Friend me or you'll strain us: understanding negative events that occur over social networking sites. CyberPsychology, Behavior, and Social Networking 2011; 14:425-432.

18. Rainie L, Lenhart A, Smith A. (2012) The tone of life on social networking sites [Internet]. Washington, DC: Pew Research Center's Internet \& American Life Project. www.pewinternet .org/Reports/2012/Social-networking-climate.aspx (accessed May 22, 2012).

19. Nie NH, Erbring L. (2000) Internet and society: a preliminary report. Stanford, CA: Stanford Institute for the Quantitative Study of Society.

20. Kraut R, Patterson M, Lundmark V, et al. Internet paradox: a social technology that reduces social involvement and psychological well-being? American Psychologist 1998; 53: 1017-1031.

21. Robinson JP, Martin S. IT use and declining social capital? Journal of Social Science Computer Review 2010; 28:45-63.

22. Sproull L, Kiesler S. Computers, networks and work. Scientific American 1991; 265:116-123.

23. Caplan SE. A social skill account of problematic Internet use. Journal of Communication 2005; 55:721-736.

24. Mehdizadeh S. Self-presentation 2.0: narcissism and selfesteem on Facebook. CyberPsychology, Behavior, and Social Networking 2010; 13:357-364.

25. Carpenter CJ. Narcissism on Facebook: self-promotional and anti-social behavior. Personality and Individual Differences 2011; 52:487-491.

26. Chou HT, Edge N. They are happier and having better lives than I am: the impact of using Facebook on perceptions of others' lives. CyberPsychology, Behavior, and Social Networking 2012; 15:117-121.

27. Kawachi I, Kennedy BP, Wilkinson RG. Crime: social disorganization and relative deprivation. Social Science and Medicine 1999; 48:719-731.

28. Farace RV, Monge PR, Russell HM. (1977) Communicating and organizing. Reading, MA: Addison-Wesley.
29. Edmunds A, Morris A. The problem of information overload in business organisations: a review of the literature. International Journal of Information Management 2000; 20:17-28.

30. Deutsch KW. On social communication and the metropolis. Daedalus 1961; 90:99-110.

31. Malhotra NK, Jain AK, Lagakos SW. The information overload controversy: an alternative viewpoint. Journal of Marketing 1982; 46:27-37.

32. Schick AG, Gordon LA, Haka S. Information overload: a temporal approach. Accounting Organizations and Society 1990; 15:199-220.

33. Eysenbach G. What is e-health? Journal of Medical Internet Research 2011; 3:e20.

34. Eppler MJ, Mengis J. The concept of information overload: a review of literature from organization science, accounting, marketing, MIS, and related disciplines. The Information Society: An International Journal 2004; 20:325-344.

35. Misra S, Stokols D. Psychological and health outcomes of perceived information overload. Environment and Behavior 2011; first published on April 17, 2011. http://eab.sagepub .com/content/early/2011/04/15/0013916511404408.full.pdf (accessed Jan. 1, 2013).

36. Stephens KK, Davis J. The social influences on electronic multitasking in organizational meetings. Management Communication Quarterly 2009; 23:63-83.

37. Cho J, Ramgolam DI, Schaefer KM, Sandlin AN. The rate and delay in overload: an investigation of communication overload and channel synchronicity on identification and job satisfaction. Journal of Applied Communication Research 2011; 39:38-54.

38. boyd dm. (2007) Why youth (heart) social network sites: the role of networked publics in teenage social life. In Buckingham D, ed. MacArthur Foundation Series on Digital LearningYouth, identity, and digital media volume. Cambridge, MA: MIT Press.

39. Facebook, Inc. (2012) Registration Statement on Form S-1. Washington, DC: United States Securities and Exchange Commission. http://sec.gov/Archives/edgar/data/1326801/ 000119312512034517/d287954ds1.htm (accessed May 22, 2012).

40. Tokunaga RS. Social networking site or social surveillance site? Understanding the use of interpersonal electronic surveillance in romantic relationships. Computers in Human Behavior 2011; 27:705-713.

41. Judge TA, Bono JE. Relationship of core self-evaluations traits-self-esteem, generalized self-efficacy, locus of control, and emotional stability - with job satisfaction and job performance: a meta-analysis. Journal of Applied Psychology 2001; 86:80-92.

42. Rosenberg M, Schooler C, Schoenbach C, Rosenberg F. Global self-esteem and specific self-esteem: different concepts, different outcomes. American Sociological Review 1995; 60:141-156.

43. Corning AF. Self-esteem as a moderator between perceived discrimination and psychological distress among women. Journal of Counseling Psychology 2002; 49:117-126.

44. Mitchell WS. Social and psychological factors associated with Internet use in the home: a uses and gratifications theory. Doctoral dissertation, Bowling Green State University, 1999.

45. Mesch GS. Family relations and the Internet: exploring a family boundaries approach. Journal of Family Communication 2006; 6:119-138.

46. Gonzalez AL, Hancock JT. Mirror, mirror on my Facebook wall: effects of exposure to Facebook on self-esteem. Cy- 
berPsychology, Behavior, and Social Networking 2011; 14:79-83.

47. Kalpidou M, Costin D, Morris J. The relationship between Facebook and the well-being of undergraduate college students. CyberPsychology, Behavior, and Social Networking 2011; 14:183-189.

48. Chung CJ, Goldhaber G. (1991) Measuring communication load: a three-dimensional instrument. Paper presented at the 41st Annual Meeting of the International Communication Association, Chicago, IL.

49. Hampton K, Goulet L, Rainie L, Purcell K. (2011) Social networking sites and our lives. Pew Research Center's Internet \& American Life Project. www.pewinternet.org/ Reports/2011/Technology-and-social-networks.aspx (accessed Jan. 1, 2013).

50. Mirowsky J, Ross C. (2003) Social causes of psychological distress, 2nd ed. New York: Aldine Transaction.

51. Kline RB. (2010) Principles and practice of structural equation modeling, 3rd ed. New York: Guilford.

52. Bollen KA. (1989) Structural equations with latent variables. New York: Wiley.

53. Hu L, Bentler PM. Cutoff criteria for fit indexes in covariance structure analysis: conventional criteria versus new alternatives. Structural Equation Modeling 1999; 6:1-55.

54. MacCallum RC, Browne MW, Sugawara HM. Power analysis and determination of sample size for covariance structure modeling. Psychological Methods 1996; 1:130-149.
55. Haughton D, Ouda J, Jansena R. Information and other criteria in structural equation model selection. Communications in Statistics: Simulation and Computation 1997; 26:1477-1516.

56. DiMaggio P, Hargittai E, Neuman WR, Robinson J. Social implications of the Internet. Annual Review of Sociology $2001 ; 27: 287-305$.

57. LaRose R, Kim JH, Peng W. (2010) Social networking: addictive, compulsive, problematic, or just another media habit? In Pappacharissi Z, ed. A networked self: identity, community, and culture on social network sites. New York: Routledge, pp. 59-81.

58. Meier RL. Communications overload: proposals from the study of a university library. Administrative Science Quarterly $1963 ; 7: 521-544$.

59. Steinfield C, Ellison NB, Lampe C. Social capital, self-esteem, and use of online social network sites: a longitudinal analysis. Journal of Applied Developmental Psychology 2008; 29:434-445.

Address correspondence to: Dr. Wenhong Chen Department of Radio-Television-Film University of Texas at Austin 2504 Whitis Ave. Stop A0800 Austin, TX 78712-1067

E-mail:wenhong_chen@mail.utexas.edu 